\title{
Transient Natural Convection in an Annulus with Thermal Radiation
}

\author{
Basant Kumar Jha1, Isah Bala Yabo², Jeng-Eng Lin ${ }^{3}$ \\ ${ }^{1}$ Department of Mathematics, Ahmadu Bello University, Zaria, Nigeria \\ ${ }^{2}$ Department of Mathematics, Usmanu Danfodiyo University, Sokoto, Nigeria \\ ${ }^{3}$ Department of Mathematics and Statistics, Georgetown University, Washington DC, USA \\ Email: basant777@yahoo.co.uk, isahby1973@gmail.com, isah.yabo@udusok.edu.ng, jengEng.Lin@georgetown.edu
}

How to cite this paper: Jha, B.K., Yabo, I.B. and Lin, J.-E. (2017) Transient Natural Convection in an Annulus with Thermal Radiation. Applied Mathematics, 8, 13511366.

https://doi.org/10.4236/am.2017.89100

Received: August 14, 2017

Accepted: September 25, 2017

Published: September 28, 2017

Copyright (c) 2017 by authors and Scientific Research Publishing Inc. This work is licensed under the Creative Commons Attribution International License (CC BY 4.0). http://creativecommons.org/licenses/by/4.0/

\section{Open Access}

\begin{abstract}
The interaction of transient fully developed natural convection flow with thermal radiation inside a vertical annulus is analyzed both analytically and numerically. The Rosseland approximation is used to describe the radiative heat flux in the energy equation. The mathematical model capturing the present physical situation is highly non-linear due to the presence of radiation effect. The solution of transient model is obtained by implicit finite difference method. To check accuracy of the numerical solution, steady state solution for energy and momentum equations are derived analytically using perturbation series method. Skin-friction and Nusselt number at the outer surface of inner cylinder as well as inner surface of the outer cylinder are obtained. Selected sets of graphical results illustrating the effects of various controlling parameters involved in the problem on flow formation are discussed.
\end{abstract}

\section{Keywords}

Transient-Natural Convection, Thermal Radiation, Annulus, Perturbation, Finite Difference

\section{Introduction}

Free convective heat transfers inside concentric and eccentric annulus has received an intensive attention of researchers owing to its scientific, technological and engineering applications such as in the construction of electrical motors and generators, cooling of electronic components, nuclear reactors, thermal storage systems, heating and cooling of underground electric cables, completion of oil source and aircraft fuselage insulation. [1] considered transient natural convection heat transfer problem between two horizontal isothermal cylinders formed 
within the Boussinesq approximation and solved numerically through the vorticity-stream function approach. Numerical prediction of natural convection heat transfer in horizontal annulus where the inner cylinder is hotter than outer was reported by [2]. [3] investigated natural convection of gasses in a horizontal annulus, where the inner cylinder is heated by the application of a constant heat flux and the outer cylinder is isothermally cooled. [4] conducted an investigation on natural convection in concentric and eccentric horizontal cylindrical annuli with mixed boundary conditions. In [5], natural convection in a narrow horizontal cylindrical annulus for fluid of $\operatorname{Pr} \leq 0.3$ been investigated. Also [6] discussed the existence of dual solution and role of Prandtl number on bifurcation. [7] performed three-dimensional linear stability analysis of air in horizontal concentric annuli between concentric cylinders by using a spectral method. In [8], finite difference method in conjunction with least-squares scheme and experimental temperature data is used to predict the average heat transfer coefficient and fin efficiency on the fin of annular-fined tube. [9] carried out experimental investigation on heat transfer characteristics of Taylor-CouettePoiseuille flow in an annular channel by mounting longitudinal ribs on the rotating inner cylinder. [10] studied natural convection flow in a horizontal annulus enclosure with a transversely oscillating inner cylinder. [11] investigated transition of natural convection in an annulus between horizontal concentric cylinders theoretically by assuming two-dimensional and incompressible flow fields. [12] examined a numerical investigation on horizontal concentric annulus with open ends and conditions of either adiabatic or isothermal outer cylinder surface. [13] showed that dual steady state solutions exist above a critical Rayleigh number for free convective flows in a horizontal annulus with constant heat-flux wall. [14] discussed the effect of nanofluid on the natural convection heat transfer and fluid flow through an annular tube with an inner heat generating solid circular rod. [15] compiled a comprehensive theoretical study on natural convection heat transfer in nanofluid contained inside the horizontal annular space existing between two long concentric cylinder whose surface are maintained at different uniform temperatures, with primary scope to determine the main heat transfer features for various operating conditions, nanoparticle diameters, and solid-liquid combination. [16] conducted a numerical investigation of natural convection heat transfer in a semi-annulus enclosure filled with nanofluid using the control volume based finite element method. [17] developed and tested a discrete phase model for forced convection of nanofluids in a circular tube subjected to a uniform heat flux. [18] and [19] examined the role of magnetic field on natural convection flow of Nano-fluid using Lattice Boltzmann method. [20] studied numerically natural convection flow and heat transfer of Copper water nanofluid inside eccentric horizontal annulus while the inner and outer cylinder are kept at constant temperatures. [21] conducted an investigation on effect of static radial magnetic field on natural convection heat transfer in a horizontal cylindrical annulus enclosure filled with nanofluid using Boltzmann 
method (LBM).

\section{Mathematical Formulation}

The physical problem under consideration consists of a transient natural convection flow in an infinite vertical annulus formed by two infinite concentric vertical cylinders in presence of thermal radiation. The transient flow formation is due to sudden heating of outer surface of inner cylinder in presence of thermal radiation. The physical properties of the working fluid are assumed to be constant. A schematic diagram of the present problem is shown in Figure 1. At time $t^{\prime} \leq 0$, both the fluid cylinder are assumed to be at thesame temperature $T_{0}$ with absence of fluid motion. At time $t^{\prime}>0$, the temperature of the outer surface of inner cylinder at $r=a$ is suddenly raised to $T_{w}\left(T_{w}>T_{0}\right)$ causing transient free convection current. Since the flow is fully developed and the cylinders are of infinite length, the flow depends on radial coordinate $\left(r^{\prime}\right)$ and time $\left(t^{\prime}\right)$. Using of Boussinesqs approximation, the governing equations in dimensional form are:

$$
\begin{gathered}
\frac{\partial u^{\prime}}{\partial t^{\prime}}=\frac{v}{r^{\prime}} \frac{\partial}{\partial r^{\prime}}\left(r^{\prime} \frac{\partial u^{\prime}}{\partial r^{\prime}}\right)+g \beta\left(T^{\prime}-T_{0}\right) \\
\frac{\partial T^{\prime}}{\partial t^{\prime}}=\alpha\left[\frac{1}{r^{\prime}} \frac{\partial}{\partial r^{\prime}}\left(\frac{\partial T^{\prime}}{\partial r^{\prime}}\right)-\frac{1}{K} \frac{\partial q_{r}}{\partial r^{\prime}}\right]
\end{gathered}
$$

The radiation heat flux term in the problem is simplified by using the Rosseland approximation:

$$
q_{r}=-\frac{4 \sigma \partial T^{\prime 4}}{3 \kappa^{*} \partial y^{\prime}}
$$



Figure 1. Schematic diagram for problem under consideration. 
The initial and boundary conditions for the present problem assumed the form:

$$
\begin{aligned}
& t^{\prime} \leq 0: u^{\prime}=0, T^{\prime}=T_{0}, \text { for } a^{*} \leq r^{\prime} \leq b^{*} \\
& t^{\prime}>0:\left\{\begin{array}{l}
u^{\prime}=0, T^{\prime}=T_{w} \text { at } r^{\prime}=a^{*} \\
u^{\prime}=0, T=T_{0} \text { at } r^{\prime}=b^{*}
\end{array}\right.
\end{aligned}
$$

To obtain the solutions of Equations ((1) and (2)) subject to the conditions (4) in dimensionless form, the following appropriate dimensionless quantities are introduce to the problem:

$$
\begin{aligned}
& u=u^{\prime}\left[g \beta a^{2}\left(T_{w}-T_{0}\right)\right]^{-1}, t=\frac{t^{\prime} v}{a^{2}}, \theta=\frac{T^{\prime}-T_{0}}{T_{w}-T_{0}}, R=\frac{4 \sigma\left(T_{w}-T_{0}\right)^{3}}{\kappa^{*} K} \\
& C_{T}=\frac{T_{0}}{T_{w}-T_{0}}, \operatorname{Pr}=\frac{\nu}{\alpha}, r=\frac{r^{\prime}}{a}, \lambda=\frac{b^{*}}{a^{*}}
\end{aligned}
$$

Using the dimensionless quantities introduced in Equation (5), the dimensionless form of equation in (1) and (2) are:

$$
\begin{gathered}
\frac{\partial u}{\partial t}=\frac{1}{r} \frac{\partial}{\partial r}\left(r \frac{\partial u}{\partial r}\right)+\theta \\
\operatorname{Pr} \frac{\partial \theta}{\partial t}=\left[1+\frac{4}{3} R\left(C_{T}+\theta\right)^{3}\right] \frac{1}{r} \frac{\partial}{\partial r}\left(r \frac{\partial \theta}{\partial r}\right)+4 R\left[C_{T}+\theta\right]^{2}\left(\frac{\partial \theta}{\partial r}\right)^{2}
\end{gathered}
$$

while the dimensionless initial and boundary conditions are:

$$
\begin{aligned}
& t \leq 0: u=\theta=0 \text { for } 1 \leq r \leq \lambda \\
& t>0:\left\{\begin{array}{l}
u=0, \theta=1 \text { at } r=1 \\
u=0, \theta=0 \text { at } r=\lambda
\end{array}\right.
\end{aligned}
$$

\section{Analytical Solution}

Analytical solution is often an opportunity to validate computer routines of complicated problems and comparison with data as well as inspecting the internal consistency of mathematical models. It is of interest to reduce the nonlinear governing equations presented in the previous section to a form that can be solved analytically. A special case of the present problem that can exhibits analytical solution is the problem of steady state free-convection flow in vertical annulus in presence of thermal radiation. The resulting steady state equations and the boundary conditions for the special case can be written as:

$$
\begin{gathered}
\frac{1}{r} \frac{\mathrm{d}}{\mathrm{d} r}\left(r \frac{\mathrm{d} u}{\mathrm{~d} r}\right)+\theta=0 \\
\frac{1}{r} \frac{\mathrm{d}}{\mathrm{d} r}\left(r \frac{\mathrm{d} \theta}{\mathrm{d} r}\right)\left[1+\frac{4}{3} R\left(C_{T}+\theta\right)^{3}\right]+4 R\left[C_{T}+\theta\right]^{2}\left(\frac{\mathrm{d} \theta}{\mathrm{d} r}\right)^{2}=0
\end{gathered}
$$

The relevant boundary conditions to be satisfied are:

$$
\left\{\begin{array}{l}
u=0 ; \theta=1 ; \text { at } r=1 \\
u=0 ; \theta=0 ; \text { at } r=\lambda
\end{array}\right.
$$


We approximate solution to Equations ((9) and (10)) subject to (11) using regular perturbation method by taking power series expansion in the radiation parameter $R$.

$$
\left.\begin{array}{l}
\theta(r)=\theta_{0}(r)+R \theta_{1}(r)+0\left(R^{2}\right) \\
u(r)=u_{0}(r)+R u_{1}(r)+0\left(R^{2}\right)
\end{array}\right\}
$$

Substituting Equation (12) into Equations ((9) and (10)) and equating the like power of $R$, the required analytical expressions for the steady state velocity and temperature fields subject to boundary conditions (11) are as follows:

$$
\begin{aligned}
u(r)= & \frac{1}{4}\left[1+\frac{1}{\ln (\lambda)}\right]-\frac{1}{4}\left[r^{2}+\frac{r^{2}}{\ln (\lambda)}\right]+\frac{1}{4}\left[\frac{r^{2} \ln (r)}{\ln (\lambda)}+\frac{\lambda^{2}}{(\ln (\lambda))^{2}}\right] \\
& -\frac{1}{4}\left[\ln (r)+\frac{r^{2}}{\ln (\lambda)}\right]+R\left\{-\frac{C_{1}}{2}\left[\frac{r^{2}[\ln (r)]^{2}}{4}-\frac{r^{2}[\ln (r)]}{2}\right.\right. \\
& \left.+\frac{3 r^{2}}{8}-r^{2} \ln (\lambda)\left(\frac{5}{16}-\frac{\ln (r)}{2}\right)\right]-\frac{C_{2}}{6}\left[\frac{r^{2}[\ln (r)]^{3}}{4}-\frac{3 r^{2}[\ln (r)]^{2}}{8}\right. \\
& \left.+\frac{9 r^{2}[\ln (r)]}{8}-\frac{3 r^{2}}{4}-r^{2}[\ln (\lambda)]^{2}\left(\frac{5}{16}-\frac{\ln (r)}{2}\right)\right] \\
& -\frac{C_{3}}{12}\left[\frac{r^{2}[\ln (r)]^{4}}{4}-r^{2}[\ln (r)]^{3}+\frac{9 r^{2}[\ln (r)]^{2}}{4}-3 r^{2} \ln (r)\right. \\
+ & \left.\left.\frac{15 r^{2}}{8}-r^{2}[\ln (\lambda)]^{3}\left(\frac{5}{16}-\frac{\ln (r)}{2}\right)\right]+C_{4} \ln (r)+C_{5}\right\} \\
\theta(r)= & 1-\frac{\ln (r)}{\ln (\lambda)}+R\left\{\frac{C_{1}[\ln (r)]}{2}[\ln (r)-\ln (\lambda)]+\frac{C_{2}[\ln (r)]}{6}\right. \\
& \left.\times\left[[\ln (r)]^{2}-[\ln (\lambda)]^{2}\right]+\frac{C_{3}[\ln (r)]}{12}\left[[\ln (r)]^{3}-[\ln (\lambda)]^{3}\right]\right\}
\end{aligned}
$$

From (13), the steady-state skin frictions at the outer surface of inner cylinder and inner surface of the outer cylinder of the annulus are:

$$
\begin{aligned}
\tau_{1}=\left.\frac{\mathrm{d} u}{\mathrm{~d} r}\right|_{r=1}= & -\frac{3}{4}[1+\ln (\lambda)]+R\left\{\frac{C_{1}}{2}\left(\frac{1}{4}+\frac{21}{40}[\ln (\lambda)]\right)\right. \\
& \left.+\frac{C_{2}}{6}\left(\frac{3}{8}+\frac{21}{40}[\ln (\lambda)]^{2}\right)+\frac{C_{3}}{12}\left(3+\frac{21}{40}[\ln (\lambda)]^{3}\right)+C_{4}\right\} \\
\tau_{\lambda}= & \left.\frac{\mathrm{d} u}{\mathrm{~d} r}\right|_{r=\lambda}=-\frac{1}{4}\left(\frac{2 \lambda^{2}+1}{\lambda}\right)-\frac{3}{4}\left(\frac{\lambda}{\ln (\lambda)}\right)+\frac{1}{2}(\lambda) \\
+ & R\left\{-\frac{C_{1}}{2}\left[\frac{\lambda(\ln (\lambda))^{2}}{4}-2 \lambda \ln (\lambda)\left(\frac{5}{16}-\frac{\ln (\lambda)}{2}\right)-\frac{\lambda}{4}\right]\right.
\end{aligned}
$$




$$
\begin{aligned}
& -\frac{C_{2}}{6}\left[\frac{\lambda(\ln (\lambda))^{3}}{2}+\frac{\lambda(\ln (\lambda))^{2}}{2}+\frac{3 \lambda \ln (\lambda)}{2}-\frac{3 \lambda}{8}\right. \\
& \left.-2 \lambda \ln (\lambda)\left(\frac{5}{16}-\frac{\ln (\lambda)}{2}\right)\right]-\frac{C_{3}}{12}\left[\frac{\lambda(\ln (\lambda))^{4}}{2}-\lambda(\ln (\lambda))^{3}\right. \\
& \left.\left.-\frac{15 \lambda(\ln (\lambda))^{2}}{8}-\frac{3 \lambda \ln (\lambda)}{2}-3 \lambda-2 \lambda(\ln (\lambda))^{3}\left(\frac{5}{16}-\frac{\ln (\lambda)}{2}\right)\right]+\frac{C_{4}}{\lambda}\right\}
\end{aligned}
$$

Equally from (14), the steady state of heat transfers at the outer surface of inner cylinder and inner surface of outer cylinder of the annulus are:

$$
\begin{aligned}
& N u_{1}=-\left.\frac{\mathrm{d} \theta}{\mathrm{d} r}\right|_{r=1}=\frac{1}{\ln (\lambda)}+R\left\{\frac{C_{1} \ln (\lambda)}{2}+\frac{C_{2}(\ln (\lambda))^{2}}{6}+\frac{C_{3}(\ln (\lambda))^{3}}{12}\right\} \\
& N u_{\lambda}=\left.\frac{\mathrm{d} \theta}{\mathrm{d} r}\right|_{r=\lambda}=-\frac{1}{\lambda \ln (\lambda)}+R\left\{\frac{C_{1}}{2} \frac{\ln (\lambda)}{\lambda}+\frac{C_{2}}{3} \frac{(\ln (\lambda))^{2}}{\lambda}+\frac{C_{3}}{4} \frac{(\ln (\lambda))^{3}}{\lambda}\right\}
\end{aligned}
$$

\section{Numerical Procedure}

The momentum and energy equations given in Equations ((6) and (7)) are solved numerically using implicit finite difference method. The time derivatives in both equations are approximated using backward difference formula as:

$$
\begin{aligned}
& \frac{\partial u}{\partial t}\left(r_{i}, t_{j}\right) \approx \frac{u\left(r_{i}, t_{j}\right)-u\left(r_{i}, t_{j-1}\right)}{\Delta t}+O\left((\Delta t)^{2}\right) \\
& \frac{\partial \theta}{\partial t}\left(r_{i}, t_{j}\right) \approx \frac{\theta\left(r_{i}, t_{j}\right)-\theta\left(r_{i}, t_{j-1}\right)}{\Delta t}+O\left((\Delta t)^{2}\right)
\end{aligned}
$$

while the first and second order space derivatives are approximated by the central difference formula.

$$
\begin{gathered}
\frac{\partial \theta}{\partial r}\left(r_{i}, t_{j}\right) \approx \frac{\theta\left(r_{i+1}, t_{j}\right)-\theta\left(r_{i-1}, t_{j}\right)}{2(\Delta r)}+o\left((\Delta r)^{2}\right) \\
\frac{\partial^{2} u}{\partial r^{2}}\left(r_{i}, t_{j}\right) \approx \frac{u\left(r_{i+1}, t_{j}\right)-2 u\left(r_{i}, t_{j}\right)+u\left(r_{i-1}, t_{j}\right)}{(\Delta r)^{2}}+O\left((\Delta r)^{2}\right) \\
\frac{\partial^{2} \theta}{\partial r^{2}}\left(r_{i}, t_{j}\right) \approx \frac{\theta\left(r_{i+1}, t_{j}\right)-2 \theta\left(r_{i}, t_{j}\right)+\theta\left(r_{i-1}, t_{j}\right)}{(\Delta y)^{2}}+O\left((\Delta r)^{2}\right)
\end{gathered}
$$

Replacing $j$ by $j+1$ in (19), (20), (22) and (23) gives an iterative system, which does not restrict the time step. Thus the transport Equations ((6) and (7)) at the grid point $(i, j)$ are linearized. The momentum Equation reads:

$$
\frac{u_{i}^{j+1}-u_{i}^{j}}{\Delta t}=\frac{u_{i-1}^{j+1}-2 u_{i}^{j+1}+u_{i+1}^{j+1}}{(\Delta r)^{2}}+\frac{1}{r(i)} \frac{u_{i+1}^{j}-u_{i-1}^{j}}{2(\Delta r)}+\theta_{i}^{j}
$$




$$
\begin{aligned}
\frac{\theta_{i}^{j+1}-\theta_{i}^{j}}{\Delta t}= & \frac{1}{\operatorname{Pr}}\left(1+\frac{4}{3} R\left[C_{T}+\theta_{i}^{j}\right]^{3}\right)\left[\frac{\theta_{i+1}^{j+1}-2 \theta_{i}^{j+1}+\theta_{i+1}^{j+1}}{(\Delta r)^{2}}+\frac{1}{r(i)} \frac{\theta_{i+1}^{j}-\theta_{i-1}^{j}}{2(\Delta r)}\right] \\
& +\frac{4}{\operatorname{Pr}} R^{2}\left(C_{T}+\theta_{i}^{j}\right)^{2}\left[\frac{\theta_{i+1}^{j}-\theta_{i-1}^{j}}{2(\Delta r)}\right]^{2}
\end{aligned}
$$

\section{Results and Discussion}

The dimensionless mathematical model representing the transient natural convection flow in an annulus with thermal radiation is solved numerically using finite difference method. The problem examines two fluids air $(\operatorname{Pr}=0.71)$ and water $(\operatorname{Pr}=7.0)$ taking into account the influence of thermal radiation parameter $R$ and temperature difference parameter $C_{T}$. The numerical scheme is validated using the steady state analytical solution derived by perturbation method.Choosing small perturbation parameter $R=0.1$, the results are found in good agreement between numerical and analytical solution at large value of time as depicted in Figure 2. The present parametric study has been performed over reasonable ranges of $0.05 \leq t \leq 8.5$ and $0 \leq R \leq 0.8$ with $r=2$ so as to capture the transient behavior of both velocity and temperature. Besides, all other parameters are taken arbitrarily. The result that clearly reports the influence of the flow governing parameters on velocity, temperature, skin friction and Nusselt number has been shown graphically in Figures 3-10.

Figure 3 represents transient and steady state velocity for different values of temperature difference parameter $\left(C_{T}\right)$ and time $(t)$. It is observed that as the values of $C_{T}$ increases the velocity increases. Also as time increases the velocity increases and finally attains its steady state value. A comparison of Figure 3(a) and Figure 3(b) reveals that velocity is inversely proportional to Prandtl number of the fluid. This is physically true since penetration of heat is low in case of
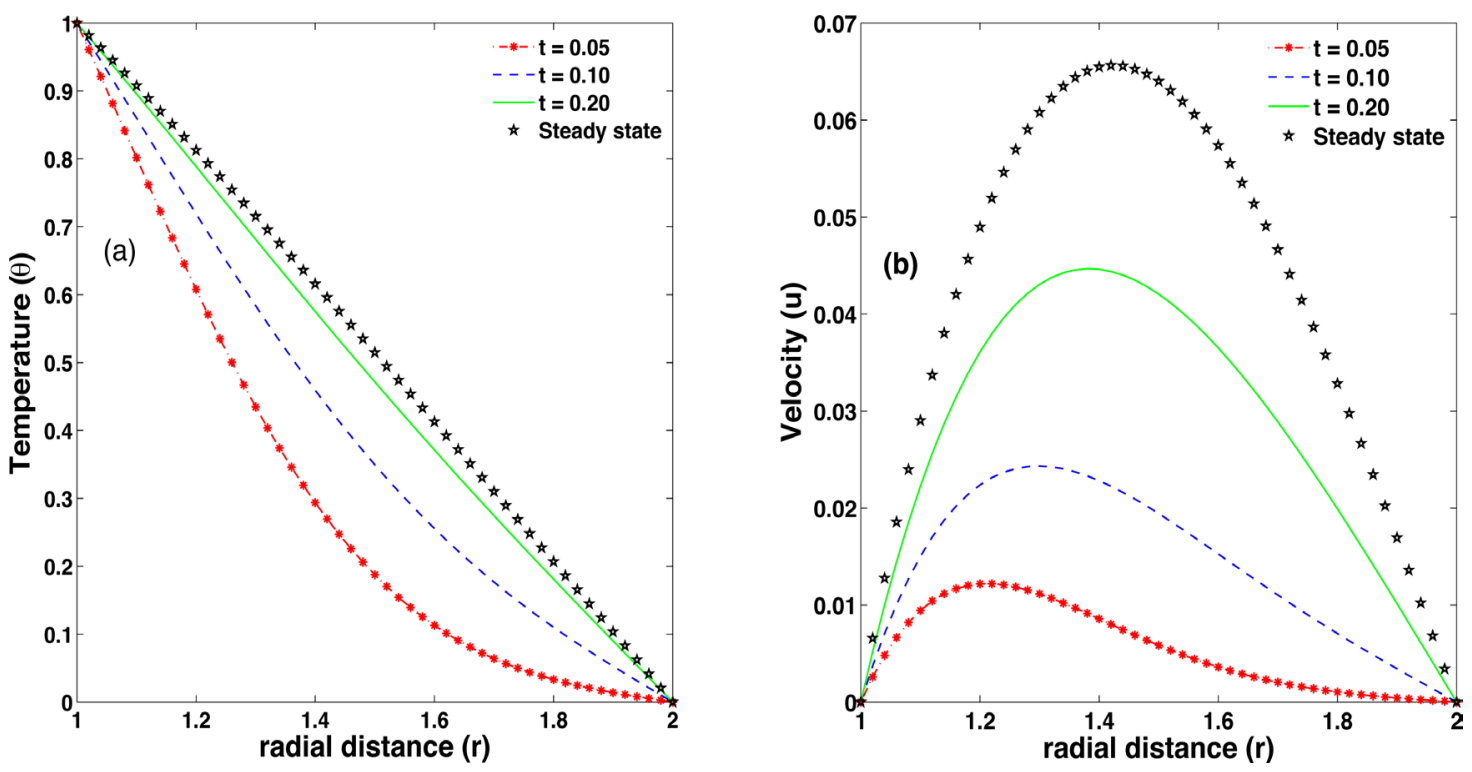

Figure 2. Temperature and Velocity Profiles $\left(R=0.01, C_{T}=0.01\right)$. 

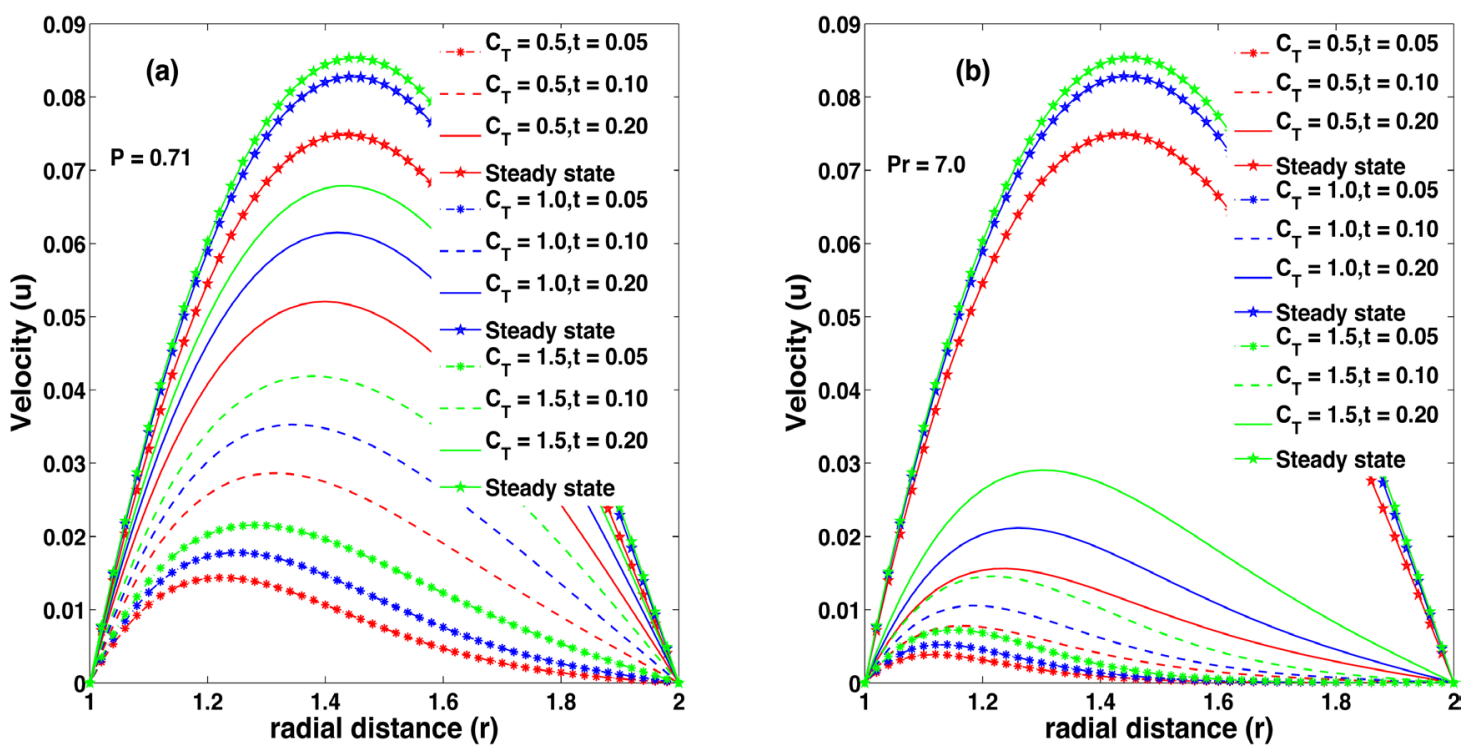

Figure 3. Velocity profile $(R=0.2)$.
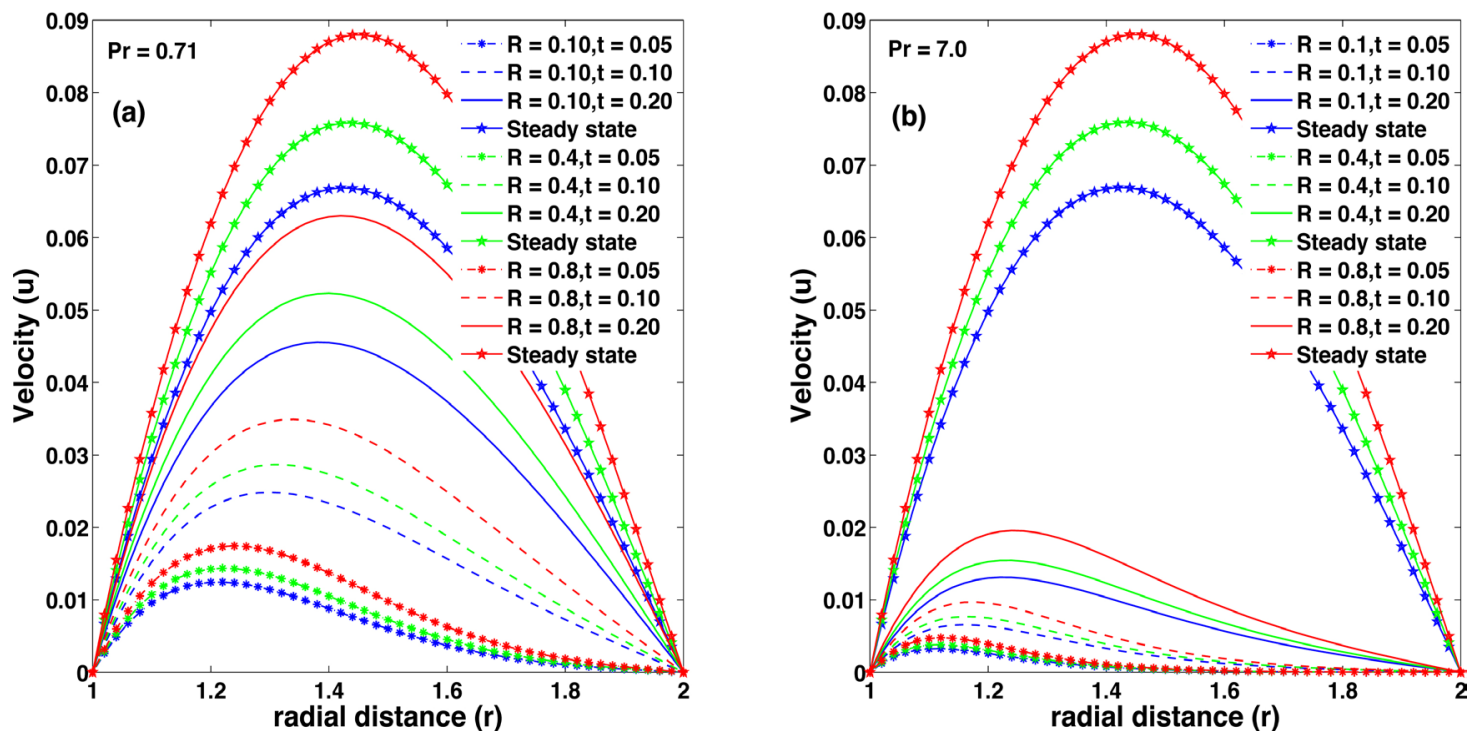

Figure 4. Velocity profile $\left(C_{T}=0.2\right)$.

higher value of $\operatorname{Pr}$ which create weak convection current inside the annulus.

Figure 4 depicts the variations of transient and steady state velocity for different values of the radiation parameter $(R)$ and time $(t)$. It is recorded from these Figure 4(a) and Figure 4(b) that, as $R$ increases, velocity increases. The physical fact is that, an increase in radiation adds more heat to the fluid leading to an increase in convection current, which causes velocity increase. These figures also report that as time increases the velocity for both air and water increases and attains steady state. During the course of numerical computation, it was observed that the time required to reach steady state is directly proportional to Prandtl number of the fluid.

Figure 5(a) and Figure 5(b) illustrate the influence of temperature difference 
parameter $\left(C_{T}\right)$ and time $(t)$ on temperature profile. It is observed from Figure 5 that as the value of $C_{T}$ is increased there is a corresponding increase in the temperature of the fluid. In addition temperature increases as dimensionless time increases and finally reach it steady state value.

From Figure 6(a) and Figure 6(b) it is clear that, as $R$ increases, temperature observed to increase. Also as time increases, the temperature increases and finally attains its steady state value.

The variation of skin friction for different values of time and temperature difference parameter $\left(C_{T}\right)$ is presented in Figure 7(a), Figure 7(b) $(\mathrm{Pr}=0.71)$ and Figure 8(a), Figure 8(b) $(\operatorname{Pr}=7.0)$. From these figures, it is observed that as $C_{T}$ increases, skin friction increases at the outer surface of the inner cylinder

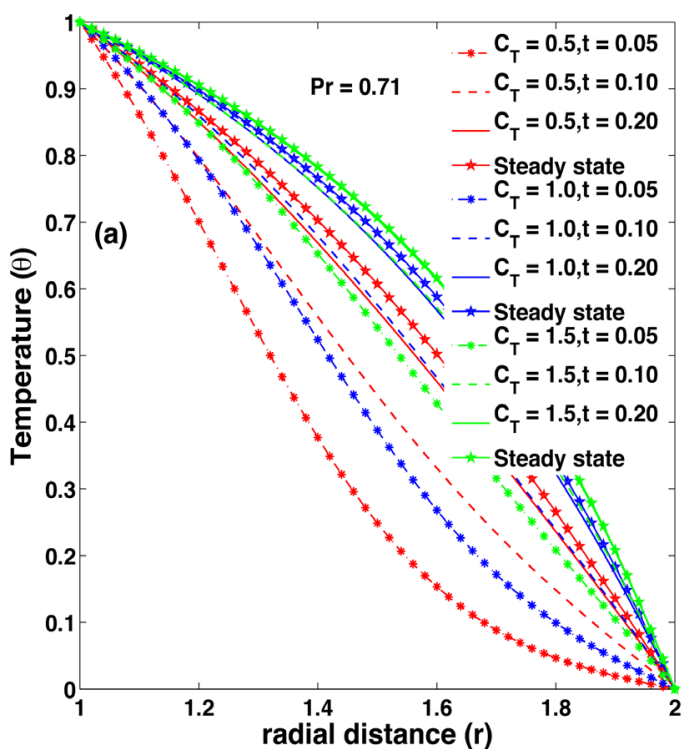

Figure 5. Temperature profile $(R=0.1)$.

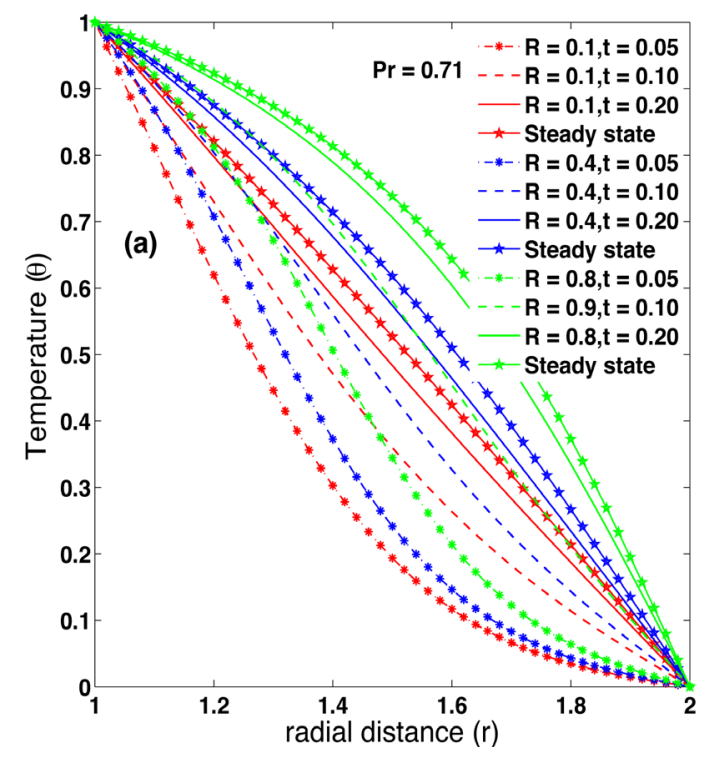

Figure 6. Temperature profile $\left(C_{T}=0.2\right)$.
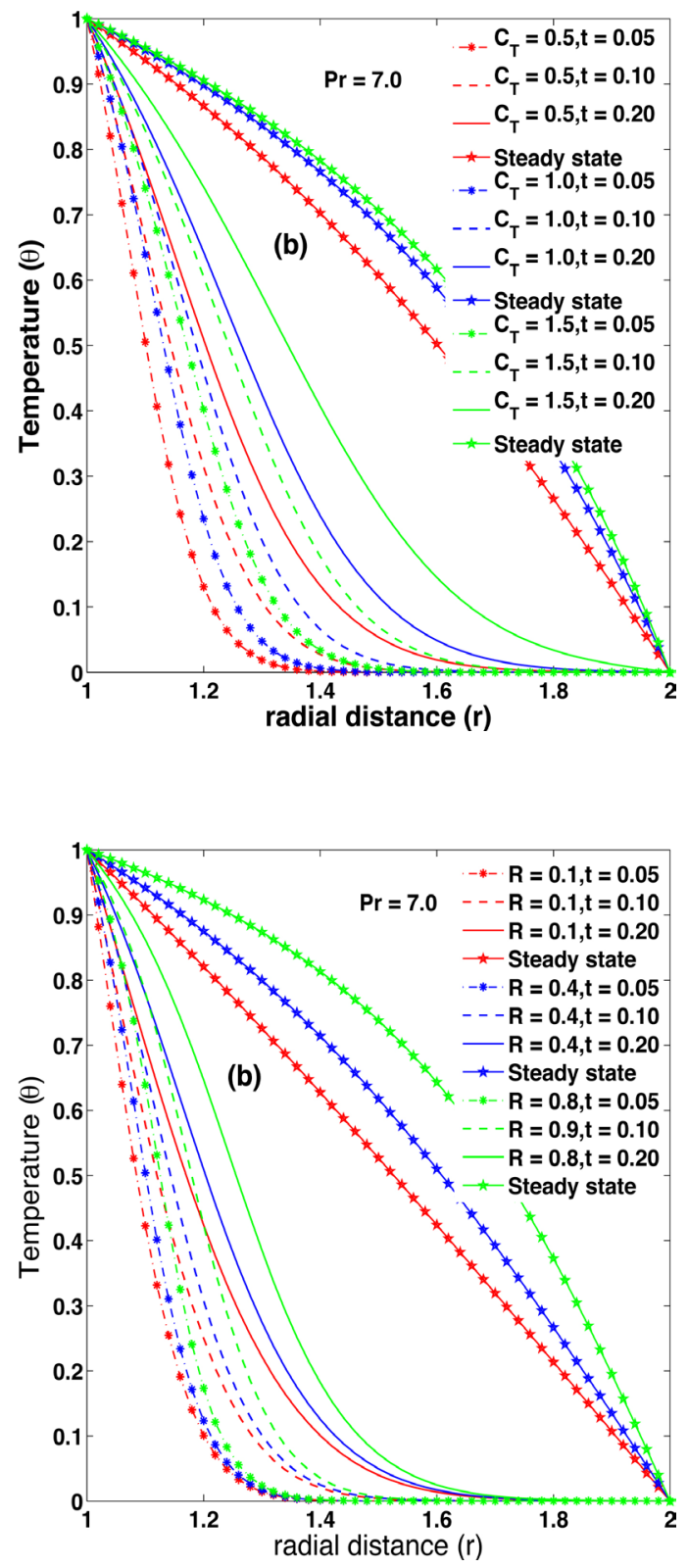

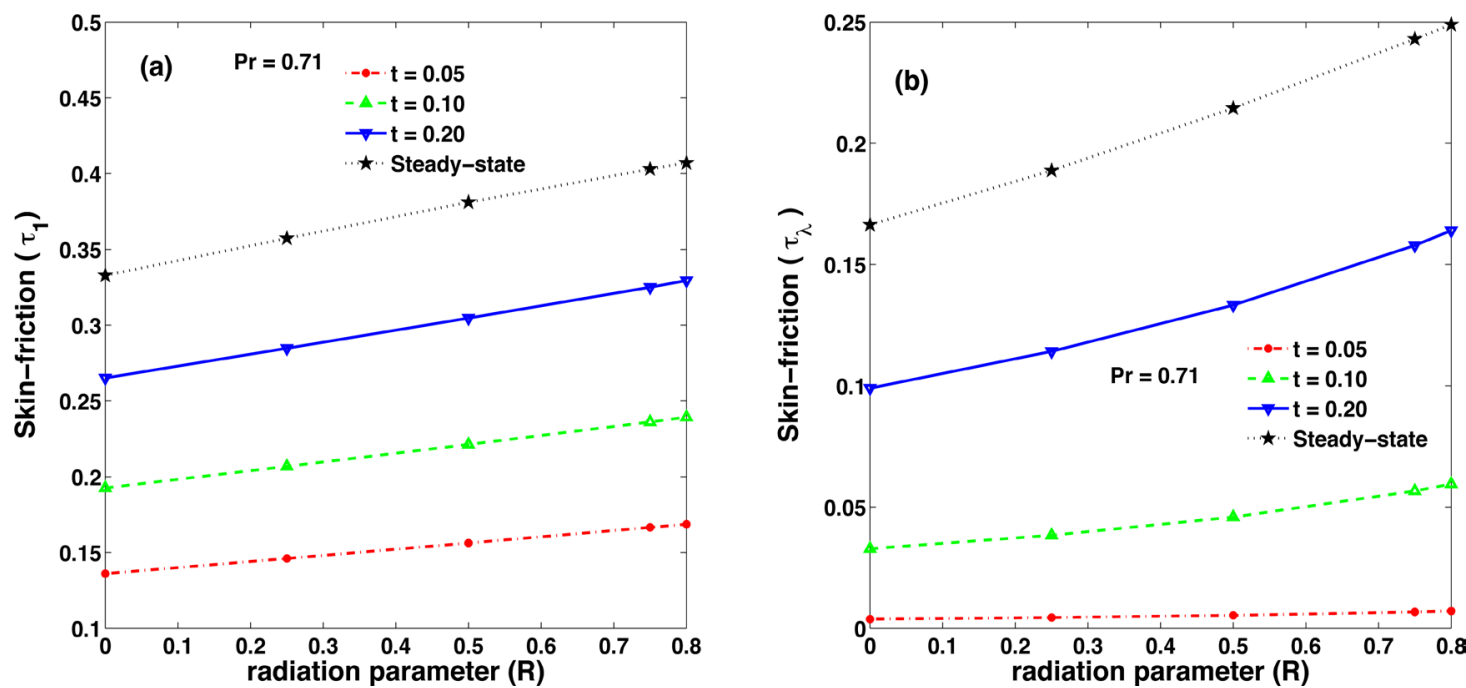

Figure 7. The variation of skin friction with $C_{T}$ and $t$ : (a) at the outer surface of the inner cylinder $(r=1)$ and (b) at the inner surface of the outer cylinder $(r=2)$ when $\operatorname{Pr}=0.71$.


Figure 8. The variation of skin friction with $C_{T}$ and $t$. (a) at the outer surface of the inner cylinder $(r=1)$ and (b) at the inner surface of the outer cylinder $(r=2)$ when $\operatorname{Pr}=7.0$.

$(r=1)$ and inner surface of the outer cylinder $(r=2)$ respectively. However, the values of skin friction are higher at the outer surface of the inner cylinder $(r=1)$ in comparison to the skin friction at the inner surface of the outer cylinder $(r=2)$. In addition, as time increases skin friction increases and finally reached its steady state value.

From Figure 9(a), Figure 9(b) $(\operatorname{Pr}=0.71)$ and Figure 10(a), Figure 10(b) $(P r=7.0)$ it is evident that skin friction at the outer surface of inner cylinder as well as the inner surface of outer cylinder increases with increase in radiation parameter $(R)$. Also as time increases the skin friction increases and achieved its steady state value. It is interesting to mention that skin friction is high for small value of $\mathrm{Pr}$. This is consistent with the fact that as Prandtl number decreases 
velocity increases.

Figure 11(a), Figure 11(b) and Figure 12(a), Figure 12(b) show the variation of the Nusselt number with $C_{T}$ and $(t)$ respectively. As illustrated in Figure 11(a) and Figure 12(a), the Nusselt number decreases with increase in $C_{T}$ and $t$ at the outer surface of inner cylinder $(r=1)$, while the result is just converse at the inner surface of the outer cylinder $(r=2)$. From these figures it is also clear that rate of heat transfer is higher for air in comparison to water. In fact the values of Nusselt number in Figure 11(a), Figure 11(b) $(\operatorname{Pr}=0.71)$ are significantly higher in comparison with Figure 12(a), Figure 12(b) $(\operatorname{Pr}=7.0)$ for small values of dimensionless time $t$.
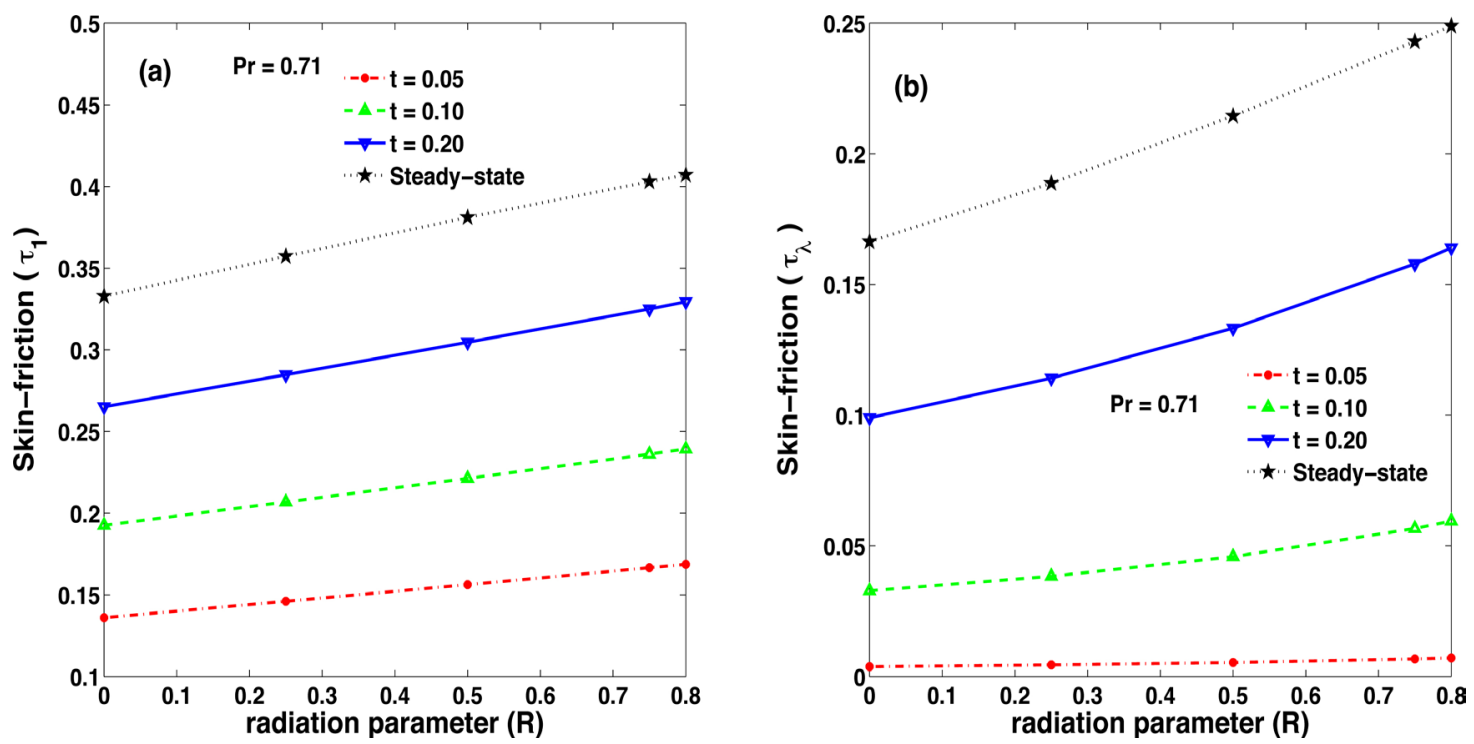

Figure 9. The variation of skin friction with $R$ and $t$ : (a) at the outer surface of the inner cylinder $(r=1)$ and (b) at the inner surface of the outer cylinder $(r=2)$ when $\operatorname{Pr}=0.71$.
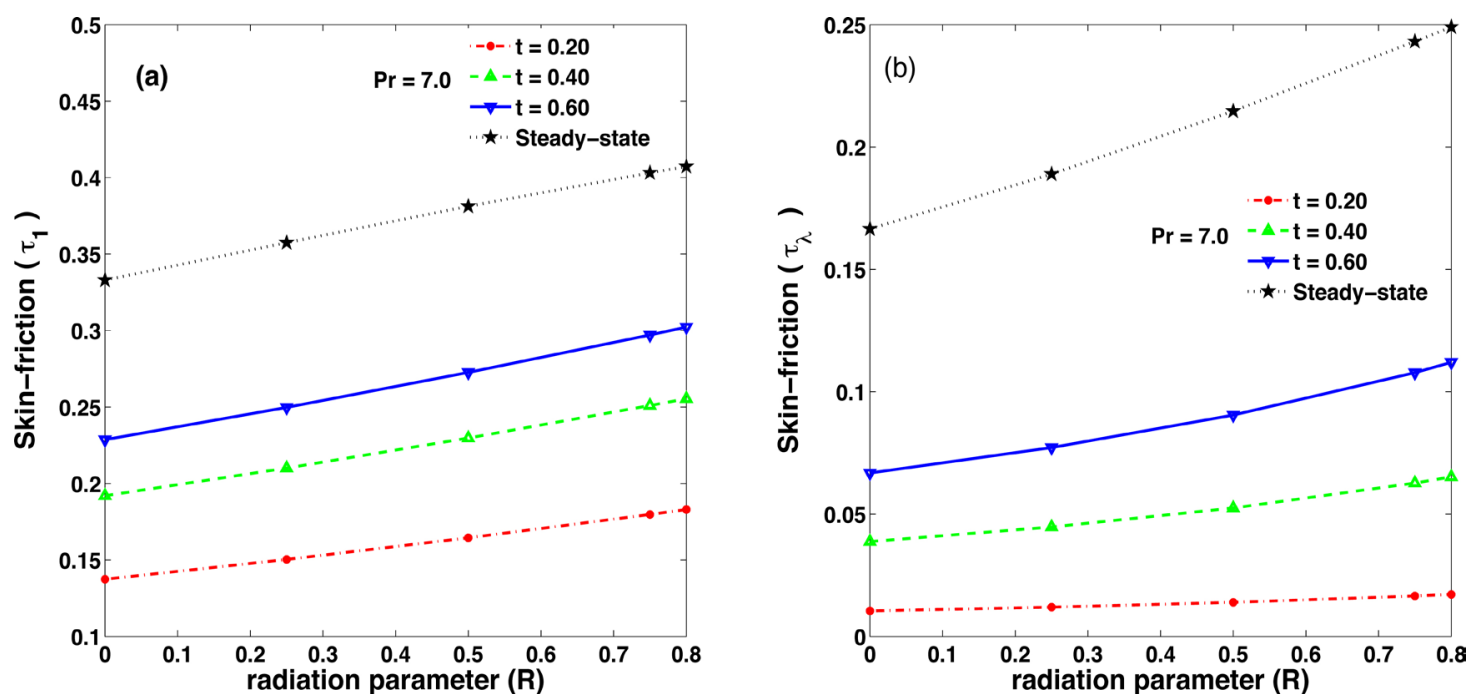

Figure 10. The variation of skin friction with $R$ and $t$. (a) at the outer surface of the inner cylinder $(r=1)$ and (b) at the inner surface of the outer cylinder $(r=2)$ when $\operatorname{Pr}=7.0$. 

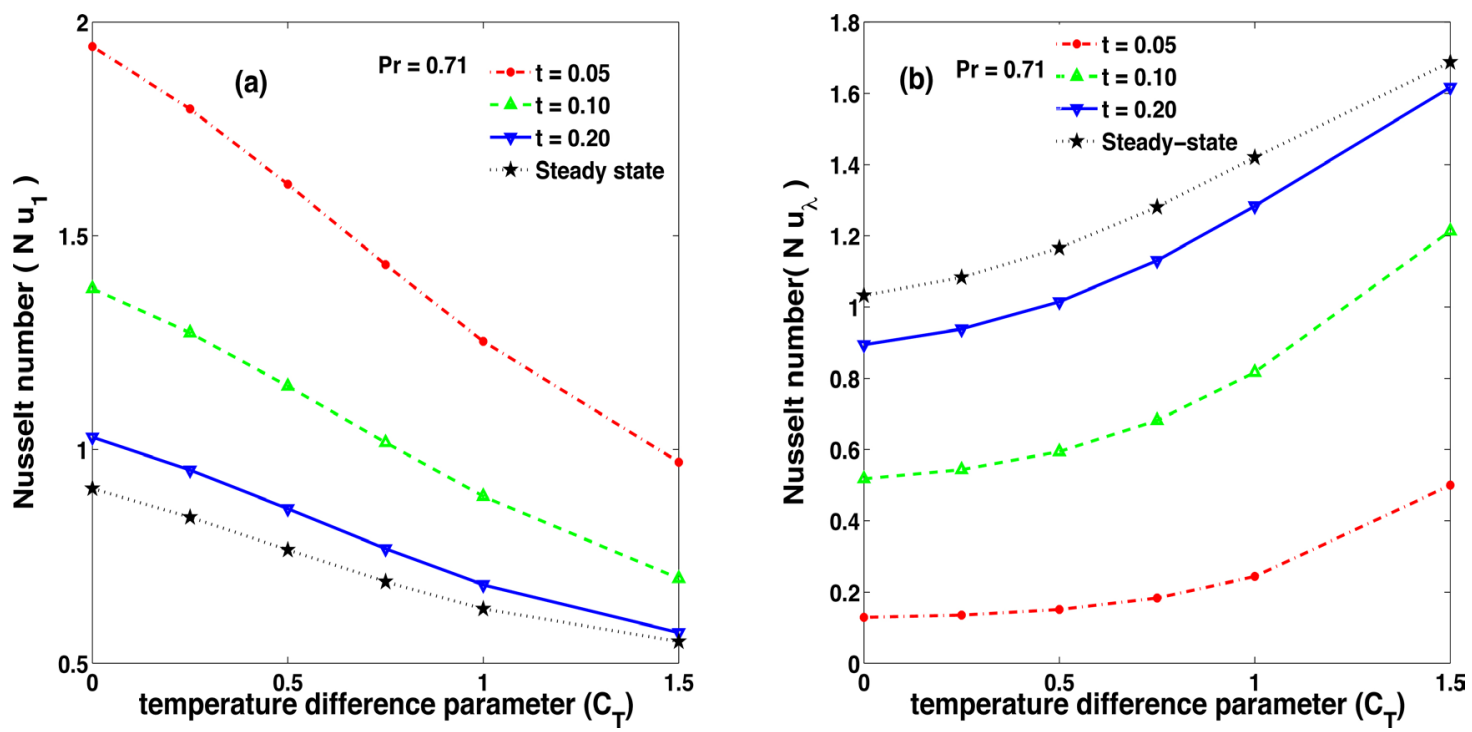

Figure 11. The variation of the Nusselt number with $C_{T}$ and: (a) at the outer surface of the inner cylinder $(r=1)$ and (b) at the inner surface of the outer cylinder $(r=2)$ when $\operatorname{Pr}=0.71$.
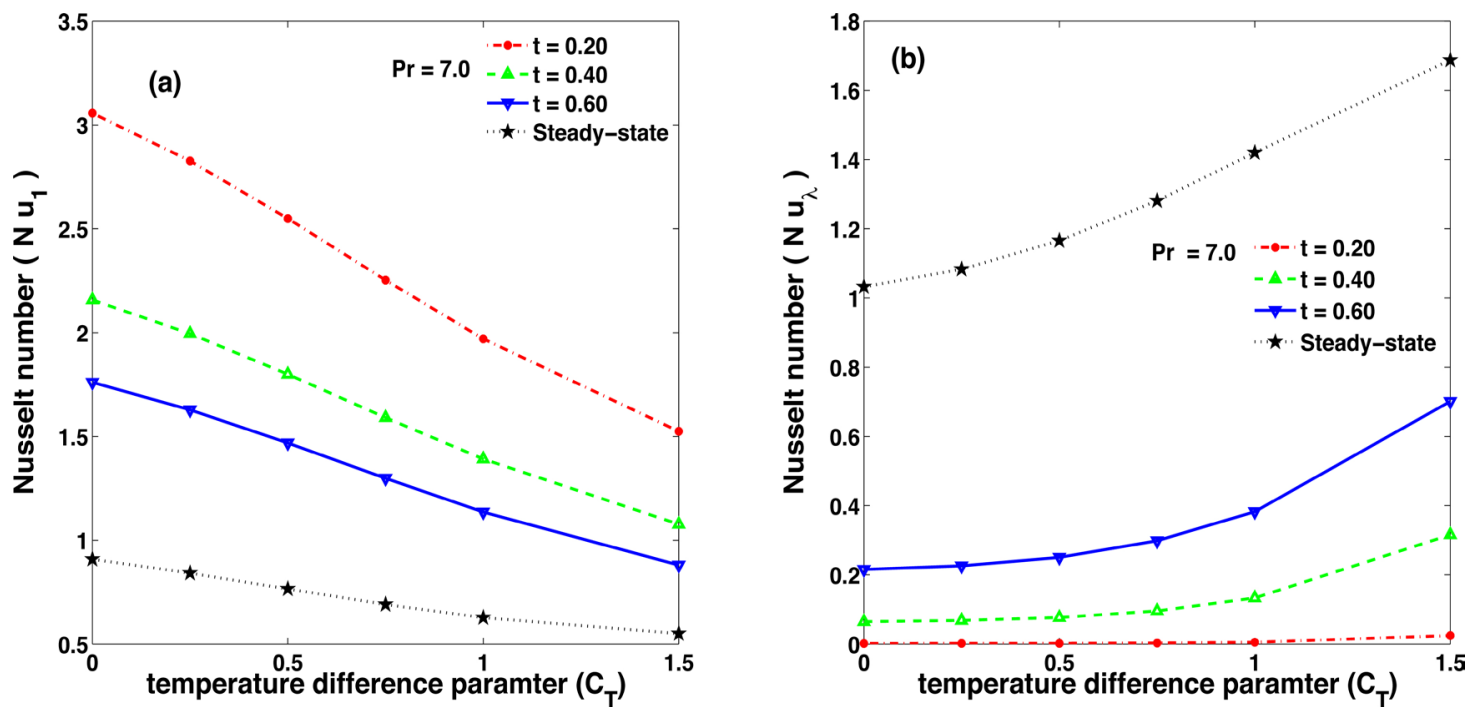

Figure 12. The variation of the Nusselt number with $C_{T}$ and: (a) at the outer surface of the inner cylinder $(r=1)$ and (b) at the inner surface of the outer cylinder $(r=2)$ when $\operatorname{Pr}=7.0$.

Figure 13(a), Figure 13(b) $(\operatorname{Pr}=0.71)$ and Figure 14(a), Figure 14(b) $(P r=7.0)$ shows the variation of Nusselt number for varying values of $R$ and time $t$ respectively. In Figure 13(a) and Figure 14(a), the Nusselt number is significantly higher for small values of $R$ and decreases with increase in dimensionless time $(t)$ to zero with increase in $R$ at the outer surface of inner cylinder $(r=1)$, while at the inner surface of the outer cylinder $(r=2)$ Nusselt number increases with both and as illustrated in Figure 13(b) and Figure 14(b).

\section{Conclusions}

The effect of temperature difference, thermal radiation and Prandtl number on 

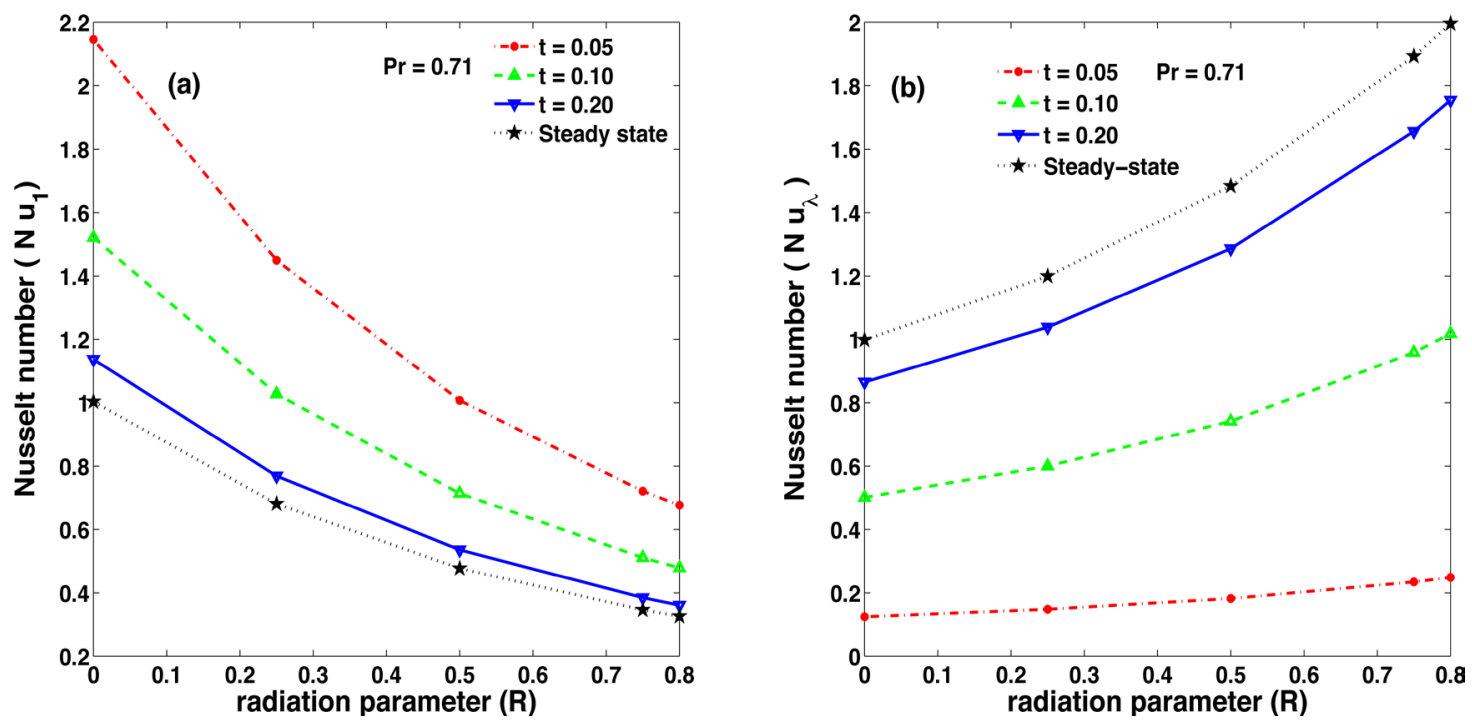

Figure 13. The variation of the Nusselt number with $R$ and: (a) at the outer surface of the inner cylinder $(r=1)$ and (b) at the inner surface of the outer cylinder $(r=2)$ when $\operatorname{Pr}=0.71$.
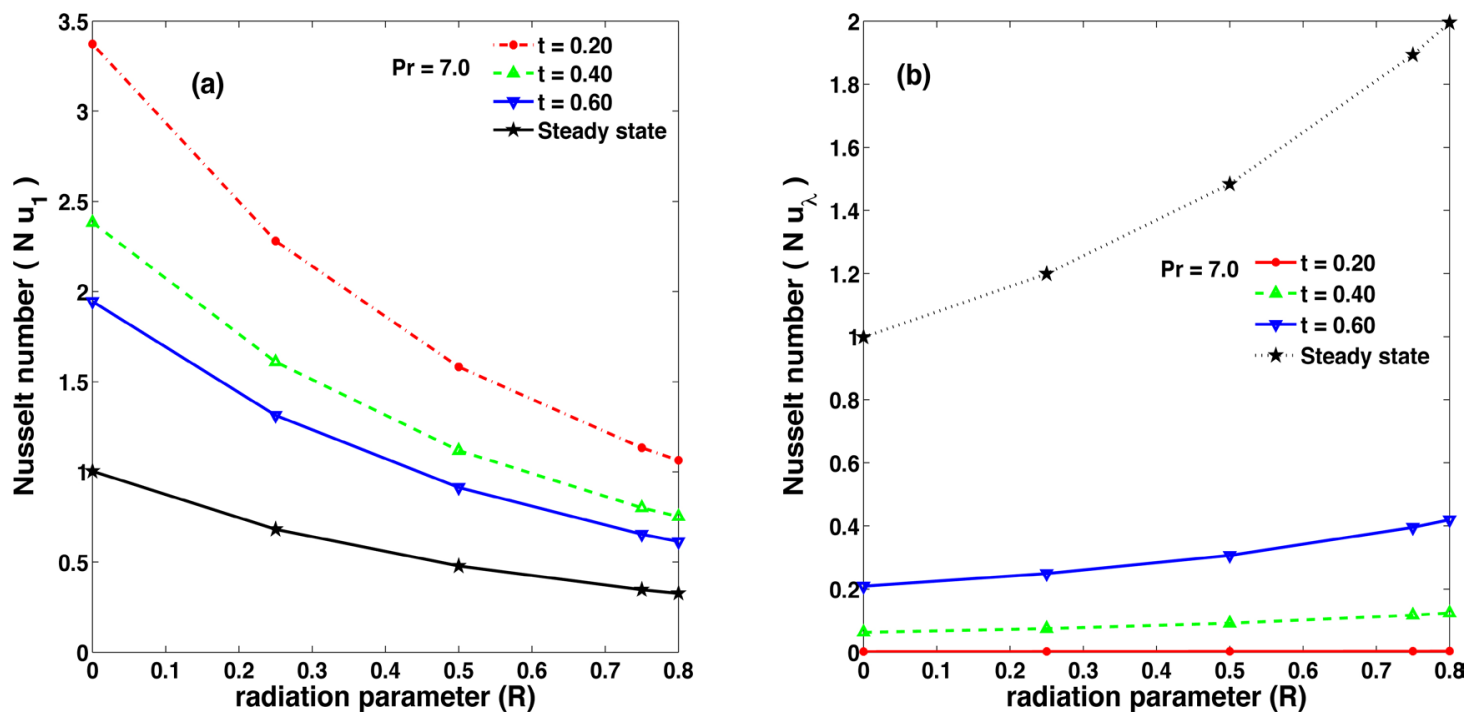

Figure 14. The variation of the Nusselt number with $R$ and: (a) at the outer surface of the inner cylinder $(r=1)$ and (b) at the inner surface of the outer cylinder $(r=2)$ when $\operatorname{Pr}=7.0$.

transient-natural convection flow inside vertical annulus is analysed analytically as well as numerically. The expression for velocity, temperature, skin-friction and Nusselt number for the nonlinear partial differential equation are obtained analytically by the well-known perturbation series method under steady state operating condition. The numerical solution is obtained by implicit finite difference method for transient situation. The outcome of the result shows that:

1) Velocity and temperature increase with increase of thermal radiation and temperature difference parameter.

2) During transient state, the maximum value of velocity occurs at smaller radial distance from the outer surface of inner cylinder and then decreases to 
zero asymptotically.

3) Thermal radiation and temperature difference parameter enhances the skin friction at the outer surface of inner cylinder as well as inner surface of the outer cylinder.

4) Nusselt number is higher at small values of $C_{T}$ and $R$ while decreases with increase in dimensionless time $(t)$ to zero with increase in $C_{T}$ and $R$ at the outer surface of inner cylinder $(r=1)$.

5) Nusselt number increases with increase in $C_{T}$ and $R$ and dimensionless time $(t)$ at the inner surface of outer cylinder $(r=2)$.

6) During course of this investigation, our results are found in good agreement between steady state and transient solution after some sufficiently large time.

\section{Acknowledgements}

The authors wish to thank the referees for their valuable comments to improve the quality of the paper.

\section{References}

[1] Tsui, Y.T. and Tremblay, B. (2000) On Transient Natural Convection Heat Transfer in the Annulus between Concentric, Horizontal Cylinder with Isothermal Surfaces. International Journal of Heat and Mass Transfer, 27, 103-111. https://doi.org/10.1016/0017-9310(84)90242-4

[2] Date, A.W. (1986) Numerical Prediction of Natural Convection Heat Transfer in Horizontal Annulus. International Journal of Heat and Mass Transfer, 29, 1457-1464. https://doi.org/10.1016/0017-9310(86)90060-8

[3] Kumar, R. (1988) Study of Natural Convection in Horizontal Annuli. International Journal of Heat and Mass Transfer, 31, 1137-1148. https://doi.org/10.1016/0017-9310(88)90056-7

[4] Ho, C.J., Lin, Y.H. and Chen, T.C. (1988) A Numerical Study of Natural Convection in Concentric and Eccentric Horizontal Cylindrical Annuli with Mixed Boundary Conditions. International Journal of Heat and Fluid Flow, 10, 40-47. https://doi.org/10.1016/0142-727X(89)90053-2

[5] Yoo, J.-S. (1998) Natural Convection in a Narrow Horizontal Cylindrical Annulus: $\operatorname{Pr} \leq$ 0.3 . International Journal of Heat and Mass Transfer, 41, 3055-3073. https://doi.org/10.1016/S0017-9310(98)00051-9

[6] Yoo, J. -S. (1999) Prandtl Number Effect on Bifurcation and Dual Solutions in Natural Convection in a Horizontal Annulus. International Journal of Heat and Mass Transfer, 42, 3279-3290. https://doi.org/10.1016/S0017-9310(98)00384-6

[7] Adachi, T. and Imai, S. (2007) Three-Dimension Linear Stability of Natural Convection in Horizontal Concentric Annuli. International Journal of Heat and Mass Transfer, 50, 1388-1396. https://doi.org/10.1016/j.ijheatmasstransfer.2006.09.029

[8] Chen, H. and Hsu, W. (2007) Estimation of Heat Transfer Coefficient on the Fin of Annular-Finned Tube Heat Exchangers in Natural Convection for Various Fin Spacings. International Journal of Heat and Mass Transfer, 50, 1750-1761. https://doi.org/10.1016/j.ijheatmasstransfer.2006.10.021

[9] Jeng, T., Tzeng, S. and Lin, C. (2007) Heat Transfer Enhancement of TaylorCouette-Poiseuille Flow in an Annulus by Mounting Longitudinal Ribs on the Rotating Inner Cylinder. International Journal of Heat and Mass Transfer, 50, 
381-390. https://doi.org/10.1016/j.ijheatmasstransfer.2006.06.005

[10] Alawadi, E.M. (2008) Natural Convection Flow in a Horizontal Annulus with an Oscillating Inner Cylinder Using Lagrangian-Eulerian Kinematics. Computers \& Fluids, 37, 1253-1261. https://doi.org/10.1016/j.compfluid.2007.10.011

[11] Mizushima, J., Hayashi, S. and Adachi, T. (2001) Transitions of Natural Convection in a Horizontal Annulus. International Journal of Heat and Mass Transfer, 44, 1249-1257. https://doi.org/10.1016/S0017-9310(00)00188-5

[12] Yeh, C. (2002) Numerical Investigation of the Three-Dimensional Natural Convection inside Horizontal Concentric Annulus with Specified Wall Temperature or Heat Flux. International Journal of Heat and Mass Transfer, 45, 775-784. https://doi.org/10.1016/S0017-9310(01)00191-0

[13] Yoo, J.-S. (2003) Dual Free-Convection Flows in a Horizontal Annulus with a Constant Heat Flux Wall. International Journal of Heat and Mass Transfer, 46, 2499-2503. https://doi.org/10.1016/S0017-9310(02)00539-2

[14] Shah, M., Mahmoudi, A.M. and Talebi, H. (2011) A Numerical Investigation of Conjugate-Natural Convection Heat Transfer Enhancement of a Nanofluid an Annular Tube Driven by Inner Heat Generating Solid Cylinder. International Communications in Heat and Mass Transfer, 38, 533-542. https://doi.org/10.1016/j.icheatmasstransfer.2010.12.022

[15] Cienfrini, M., Corcione, M. and Quintino, A. (2011) Natural Convection Heat Transfer of Nanofluids in Annular Spaces between Horizontal Concentric Cylinders. Applied Thermal Engineering, 31, 4055-4063. https://doi.org/10.1016/j.applthermaleng.2011.08.010

[16] Soleimani, S., Sheikholeslami, M., Ganji, D.D. and Gorji-Bandapay, M. (2012) Natural Convection Heat Transfer in a Nanofluid Filled Semi-Annulus Enclosure. International Communications in Heat and Mass Transfer, 39, 565-574. https://doi.org/10.1016/j.icheatmasstransfer.2012.01.016

[17] Tahir, S. and Mital, M. (2012) Numerical Investigation of Laminar Nanofluid Developing Flow and Heat Transfer in a Circular Channel. Applied Thermal Engineering, 39, 8-14. https://doi.org/10.1016/j.applthermaleng.2012.01.035

[18] Sheikholeslami, M., Gorji-Bandpay, M., Ganji, D.D. and Soleimani, S. (2012) Magnetic Field Effects on Natural Convection around a Horizontal Circular Cylinder inside a Square Enclosure Filled with Nanofluid. International Communications in Heat and Mass Transfer, 36, 978-986.

https://doi.org/10.1016/j.icheatmasstransfer.2012.05.020

[19] Sheikholeslami, M., Gorji-Bandpay, M., Ganji, D.D. and Soleimani, S. (2013) Effect of Magnetic Field on Natural Convection in an Inclined Half-Annulus Enclosure Filled with Cu-Water Nanofluid using CVFEM. Advanced Powder Technology, 24, 980-991. https://doi.org/10.1016/j.apt.2013.01.012

[20] Habibi Matin, M. and Pop, I. (2013) Effect of Natural Convection Flow and Heat Transfer in an Eccentric Annulus Filled by Copper Nanofluid. International Journal of Heat and Mass Transfer, 61, 353-364. https://doi.org/10.1016/j.ijheatmasstransfer.2013.01.061

[21] Ashorynejaeed, H.R., Mohamad, A.A. and Sheikholeslam, M. (2013) Magnetic Field Effects on Natural Convection Flow of a Nanofluid in a Horizontal Cylindrical Annulus using Lattice Boltzmann Method. International Journal of Thermal Sciences, 64, 240-250. https://doi.org/10.1016/j.ijthermalsci.2012.08.006 


\section{Appendix}

$$
\begin{aligned}
C_{1}= & \frac{-4\left[C_{T}^{2}+2 C_{T}+1\right]}{[\ln (\lambda)]^{2}} ; C_{2}=\frac{8\left[C_{T}+1\right]}{[\ln (\lambda)]^{3}} ; C_{3}=\frac{-4}{[\ln (\lambda)]^{4}} \\
C_{4}= & \frac{C_{1}}{2}\left[2 \lambda^{2}(\ln (\lambda))^{2}+\frac{11 \lambda^{2} \ln (\lambda)}{16}-\frac{\ln (\lambda)}{16}+\frac{3 \lambda^{2}}{8 \ln (\lambda)}-\frac{\lambda^{2}}{2}-\frac{3}{8}\right] \\
& +\frac{C_{2}}{6}\left[\frac{5 \lambda^{2}(\ln (\lambda))^{3}}{12}-\frac{5 \lambda^{2}(\ln (\lambda))^{2}}{48}-\frac{3 \lambda^{2} \ln (\lambda)}{8}-\frac{3 \lambda^{2}}{4 \ln (\lambda)}\right. \\
& \left.-\frac{(\ln (\lambda))^{2}}{16}+\frac{9 \lambda^{2}}{8}+\frac{3}{4}\right]+\frac{C_{3}}{12}\left[\frac{\lambda^{2}(\ln (\lambda))^{4}}{4}-\frac{33 \lambda^{2}(\ln (\lambda))^{3}}{172}\right. \\
& \left.-\frac{(\ln (\lambda))^{3}}{16}-\lambda^{2}(\ln (\lambda))^{2}+\frac{9 \lambda^{2} \ln (\lambda)}{4}+\frac{15 \lambda^{2}}{8 \ln (\lambda)}-3 \lambda^{2}\right] \\
C_{5}=\frac{C_{1}}{2}( & \left.\frac{3}{8}+\frac{1}{16} \ln (\lambda)\right)-\frac{C_{2}}{2}\left(\frac{3}{4}-\frac{1}{16}[\ln (\lambda)]^{2}\right)+\frac{C_{3}}{2}\left(\frac{5}{16}+\frac{1}{96}[\ln (\lambda)]^{3}\right)
\end{aligned}
$$

\section{Nomenclatures}

a radius of the inner cylinder

$b \quad$ radius of the outer cylinder

$g$ acceleration due to gravity

$C_{T} \quad$ temperature difference parameter

$\mathrm{Pr} \quad$ Prandtl number

$R \quad$ thermal radiation parameter

$t^{\prime} \quad$ time

$r^{\prime} \quad$ radial coordinate

$T_{0} \quad$ initial temperature

$t$ dimensionless time

$T_{w} \quad$ temperature of the outer surface of inner cylinder

$u \quad$ vertical component of velocity

$z^{\prime} \quad$ vertical co-ordinate, direction of flow

\section{Greek Letters}

$\begin{array}{ll}\alpha & \text { thermal diffusivity } \\ \beta & \text { coefficient of thermal expansion } \\ \kappa & \text { mean absorption coefficient } \\ K & \text { thermal conductivity } \\ \rho & \text { density of the fluid } \\ \delta & \text { Stefan-Boltzmann constant }\end{array}$


Submit or recommend next manuscript to SCIRP and we will provide best service for you:

Accepting pre-submission inquiries through Email, Facebook, LinkedIn, Twitter, etc. A wide selection of journals (inclusive of 9 subjects, more than 200 journals)

Providing 24-hour high-quality service

User-friendly online submission system

Fair and swift peer-review system

Efficient typesetting and proofreading procedure

Display of the result of downloads and visits, as well as the number of cited articles Maximum dissemination of your research work

Submit your manuscript at: http://papersubmission.scirp.org/

Or contact am@scirp.org 